Original article

\title{
ALLOMETRIC ANALYSIS OF THE PHARMACOKINETICS OF FOUR CEPHALOSPORIN ANTIBIOTICS IN MAMMALS
}

\author{
L. D. LASHEV \\ Department of Pharmacology, Physiology and Physiological Chemistry, \\ Faculty of Veterinary Medicine, Trakia University, 6000 Stara Zagora, Bulgaria
}

\section{Summary}

Lashev, L., 2017. Allometric analysis of the pharmacokinetics of four cephalosporin antibiotics in mammals. Bulg. J. Vet. Med., 20, No 1, 27-37.

\begin{abstract}
Allometric analysis of the total body clearance $\left(\mathrm{Cl}_{\mathrm{B}}\right)$, steady-state volume of distribution $\left(\mathrm{V}_{\mathrm{ss}}\right)$ and elimination half-life $\left(t_{1 / 2 \beta}\right)$ was performed for cephalexin, cefepime, cefquinone and ceftriaxone based on literature data in mammalian species. Values of $\mathrm{Cl}_{\mathrm{B}}$ and $\mathrm{V}_{\mathrm{ss}}$ show allometric dependence on body weight, while values of $t_{1 / 2 \beta}$ could not be predicted correctly after scaling toward body weight. The equations based on the calculations which could be used for estimation of the respective pharmacokinetic parameters are as follows: Cephalexin: $\mathrm{Cl}_{\mathrm{B}}=0.20 \mathrm{~W}^{1.05}$; $\mathrm{Vss}=0.32 \mathrm{~W}^{0.98}$; Cefepime: $\mathrm{t}_{1 / 2 \mathrm{~B}}=1.03 \mathrm{~W}^{0.16}$; $\mathrm{Cl}_{\mathrm{B}}=0.35 \mathrm{~W}^{0.68} ; \mathrm{V}_{\mathrm{ss}}=0.133 \mathrm{~W}^{0.99}$; Ceftriaxone: $\mathrm{t}_{1 / 2 \mathrm{\beta}}=0.83 \mathrm{~W}^{0.13} ; \mathrm{Cl}_{\mathrm{B}}=0.76 \mathrm{~W}^{0.73} ; \mathrm{V}_{\mathrm{ss}}=0.82 \mathrm{~W}^{0.79} ;$ Cefquinome: $\mathrm{Cl}_{\mathrm{B}}=0.22 \mathrm{~W}^{0.875} ; \mathrm{V}_{\mathrm{ss}}=0.298 \mathrm{~W}^{0.975}$.
\end{abstract}

Key words: allometric scaling, cefepime, cefquinome, ceftriaxone, cephalexin, pharmacokinetics

\section{INTRODUCTION}

Allometric analysis is a method for predicting the values of some pharmacokinetic parameters of drugs and to estimate dosage regimens in animal species that have not been studied so far. It has also been used in drug development (Mahmood \& Balian, 1999) and for comparison of pharmacokinetic characteristics of different substances among species (Dinev, 2008). The allometric scaling is usually conducted using data for animal species, belonging to taxonomic groups with similar physiological characteristics as birds or mammals (herbivores or carnivores)
(Pashov et al., 1997; Dinev, 2008; Haritova \& Lashev, 2009; 2012). This is based on interspecies differences in the physiology and it is aimed at predicting the specific pharmacokinetic properties of the drugs with high accuracy. Comparative interspecies pharmacokinetic scaling has been performed for a large variety of antibacterial agents (Riviere et al., 1997; Cox, 2007; Lashev \& Haritova, 2007; Haritova \& Lashev, 2009; 2012; Hunter, 2010) but not for cephalosporin antibiotics. The latter are widely used for treatment of different infections in veterinary and hu- 
man medicine. Their pharmacokinetics is extensively studied in a number of animal species after different routes of administration. These drugs have a similar distribution and differ mainly in elimination phase and especially in elimination rates depending on the species and age (Smiet et al., 2012). Considerable variations are registered after oral absorption. Cephalosporins have a volume of distribution between 0.2 and $0.5 \mathrm{~L} / \mathrm{kg}$. Binding to plasma proteins varies among the substances and species, but often has low values. Cephalosporins are metabolised at a very low extent with the exception of ceftiofur (Mordenti, 1985). The major differences between animal species are related to active transport and renal excretion. These drugs are excreted with urine mainly by tubular secretion (Forgue et al., 1987).

The objective of this study was to assess the relationships between elimination half-life, volume of distribution at steadystate, and total body clearance to body weight of four cephalosporins, used in veterinary medicine, in mammalian species by means of allometric scaling.

\section{MATERIALS AND METHODS}

The allometric analysis of pharmacokinetic parameters of cephalexin, cefquinome, ceftriaxone and cefepime was performed with data from published studies concerning healthy adult animals (Tables 1-4). Only data for intravenously administered drugs, determined by microbiological or HPLC assays, were used. The matrices of interest were serum or plasma. For analysis of each drug, data for elimination half-life $\left(t_{1 / 2 \beta}\right)$, volume of distribution at steady-state $\left(\mathrm{V}_{\mathrm{ss}}\right)$ and total body clearance $\left(\mathrm{Cl}_{\mathrm{B}}\right)$ were used. Data for body weights were collected from the same studies. All values were calculated on the basis of mean published values of pharmacokinetic parameters versus body weights of the included animals. The simple allometric approach was based on the following power function:

Table 1. Pharmacokinetic parameters of cephalexin after intravenous administration to seven mammalian species

\begin{tabular}{lccccl}
\hline Species & $\mathrm{W}(\mathrm{kg})$ & $\mathrm{t}_{1 / 2}(\mathrm{~h})$ & $\mathrm{Cl}_{\mathrm{B}}(\mathrm{L} / \mathrm{kg} / \mathrm{h})$ & $\mathrm{V}_{\mathrm{ss}}(\mathrm{L} / \mathrm{kg})$ & Reference \\
\hline Rat & 0.235 & 1.45 & 0.199 & 0.42 & Zhang et al., 2010 \\
\hline Cat & 4.95 & 1.68 & 0.14 & 0.33 & Albarellos et al., 2011 \\
\hline Dog & 25.2 & 1.96 & 0.17 & 0.37 & Chicoine et al., 2009 \\
& 12 & 1.62 & 0.22 & 0.15 & Carli et al., 1999 \\
& 11.7 & 2.26 & 0.66 & 0.19 & Prados et al., 2008 \\
Mean & 16.3 & 1.95 & 0.35 & 0.24 & \\
\hline Goat & 38.7 & 0.36 & 0.35 & 0.16 & Ambros et al., 2010 \\
\hline Buffalo & 102.5 & 2.16 & 0.14 & 0.41 & Garg et al., 1990 \\
\hline Cow & 500 & 0.58 & 0.63 & 0.39 & Soback et al., 1988 \\
& 81.5 & 3.17 & 0.178 & & Garg et al., 1996 \\
Mean & 290.7 & 1.88 & 0.404 & 0.39 & \\
\hline Horse & 523 & 2.02 & 0.20 & 0.2 & Davis et al., 2005 \\
& 425 & 1.54 & 0.24 & 0.29 & Villa et al., 2002 \\
Mean & 474 & 1.78 & 0.22 & 0.24 & \\
\hline
\end{tabular}

$\mathrm{W}$ - body weight; $\mathrm{t}_{1 / 2}$ - elimination half life; $\mathrm{Cl}_{\mathrm{B}}$ - total body clearance; $\mathrm{V}_{\mathrm{ss}}$ - steady state volume of distribution. 
Table 2. Pharmacokinetic parameters of cefepime after intravenous administration to eleven mammalian species

\begin{tabular}{lcllll}
\hline Species & $\mathrm{W}(\mathrm{kg})$ & $\mathrm{t}_{1 / 2}(\mathrm{~h})$ & $\mathrm{Cl}_{\mathrm{B}}(\mathrm{L} / \mathrm{kg} / \mathrm{h})$ & $\mathrm{V}_{\mathrm{ss}}(\mathrm{L} / \mathrm{kg})$ & References \\
\hline Mice & 0.032 & 0.38 & 1 & & Mathe et al., 2006 \\
& & 0.685 & 1.74 & 0.35 & Bu et al., 2010 \\
Mean & 0.032 & 0.53 & 1.37 & 0.35 & \\
\hline Rat & 0.33 & 0.39 & 0.65 & 0.33 & Forgue et al., 1987 \\
& & 0.65 & 0.66 & 0.38 & Forgue et al., 1987 \\
Mean & 0.33 & 0.52 & 0.65 & 0.36 & \\
\hline Rabbit & 3.1 & 1.5 & 0.12 & 0.31 & Rule et al., 2008 \\
& 2.3 & 2.94 & 0.30 & 1.17 & Abd el Aty et al., 2007 \\
Mean & 2.7 & 2.22 & 0.21 & 0.74 & \\
\hline Dog & 9.2 & 1.09 & 0.13 & 0.1 & Gardner \& Papich, 2001 \\
\hline Monkey & 5.2 & 1.8 & 0.11 & 0.25 & Forgue et al., 1987 \\
\hline Goat & 38.5 & 1.86 & 0.07 & & Prawez et al., 2010 \\
& 29.5 & 2.71 & 0.13 & 0.35 & Patani et al., 2008 \\
Mean & 34 & 2.29 & 0.1 & 0.35 & \\
\hline Cow & 68.5 & 3.7 & 0.11 & 0.43 & Patel et al., 2006 \\
& 156.8 & 2.38 & 0.07 & 0.21 & Ismail, 2005a \\
Mean & 99.6 & 1.26 & 0.1 & 0.25 & Pawar \& Sharma, 2008 \\
\hline Sheep & 108.3 & 2.45 & 0.093 & 0.3 & \\
Mean & 27.5 & 2.54 & 0.15 & 0.42 & Patel et al., 2009 \\
\hline Buffalo & 49 & 1.76 & 0.14 & 0.32 & Ismail, 2005b \\
\hline Camel & 98.25 & 2.16 & 0.145 & 0.37 & \\
\hline Horse & 475 & 2.67 & 0.086 & 0.42 & Joshi \& Sharma, 2007 \\
\hline & 492 & 2.1 & 0.04 & 0.1 & Goudah et al., 2009 \\
\hline
\end{tabular}

$\mathrm{W}$ - body weight; $\mathrm{t}_{1 / 2}$ - elimination half life; $\mathrm{Cl}_{\mathrm{B}}$ - total body clearance; $\mathrm{V}_{\mathrm{ss}}$ - steady state volume of distribution.

Table 3. Pharmacokinetic parameters of cefquinome after intravenous administration to six mammalian species

\begin{tabular}{llllll}
\hline Species & $\mathrm{W}(\mathrm{kg})$ & $\mathrm{t}_{1 / 2}(\mathrm{~h})$ & $\mathrm{Cl}_{\mathrm{B}}(\mathrm{L} / \mathrm{kg} / \mathrm{h})$ & $\mathrm{V}_{\mathrm{ss}}(\mathrm{L} / \mathrm{kg})$ & References \\
\hline Rabbit & 3.0 & 0.93 & 0.18 & 0.21 & Hwang et al., 2011 \\
\hline Dog & 21.8 & 0.85 & 0.196 & 0.20 & Limbert et al., 1991 \\
& 21.5 & 0.98 & 0.22 & 0.24 & Limbert et al., 1991 \\
& 21.2 & 0.96 & 0.191 & 0.22 & Limbert et al., 1991 \\
Mean & 21.5 & 0.93 & 0.20 & 0.22 & \\
\hline Pig & 25 & 1.64 & 0.15 & 0.31 & Liu et al., 2012 \\
& 22.5 & 1.85 & 0.26 & 0.46 & Li et al., 2008 \\
Mean & 23.8 & 1.74 & 0.30 & 0.38 & \\
\hline Sheep & 30 & 0.78 & 0.34 & 0.36 & Uney et al., 2011 \\
\hline Goat & 18 & 5.76 & 0.06 & 0.37 & Dumka et al., 2013 \\
\hline Buffalo & 123 & 3.56 & 0.06 & 0.26 & Dinakaran et al., 2013 \\
\hline Cattle & 118.5 & 1.33 & 0.13 & 0.23 & Limbert et al., 1991 \\
\hline Horse & 300 & 2.33 & 0.13 & 0.22 & Smiet et al., 2012 \\
\hline
\end{tabular}

$\mathrm{W}$ - body weight; $\mathrm{t}_{1 / 2}$ - elimination half life; $\mathrm{Cl}_{\mathrm{B}}$ - total body clearance; $\mathrm{V}_{\mathrm{ss}}$ - steady state volume of distribution. 
Allometric analysis of the pharmacokinetics of four cephalosporin antibiotics in mammals

Table 4. Pharmacokinetic parameters of ceftriaxone after intravenous administration to eleven mammalian species

\begin{tabular}{llllll}
\hline Species & $\mathrm{W}(\mathrm{kg})$ & $\mathrm{t}_{1 / 2}(\mathrm{~h})$ & $\mathrm{Cl}_{\mathrm{B}}(\mathrm{l} / \mathrm{kg} / \mathrm{h})$ & $\mathrm{V}_{\mathrm{ss}}(\mathrm{L} / \mathrm{kg})$ & References \\
\hline Mice & 0.019 & 0.49 & 9.79 & 7.16 & Wang et al., 2005 \\
\hline Rat & 0.2 & 0.67 & 0.30 & 0.22 & Lee et al., 2006 \\
& 0.225 & 0.57 & - & - & Matsui et al., 1984 \\
Mean & 0.21 & 0.62 & 0.3 & 0.22 & \\
\hline Cat & 5.51 & 1.73 & 0.37 & 0.57 & Albarelos et al., 2007 \\
\hline Dog & 19.6 & 0.88 & 0.22 & 0.28 & Rebuelto et al., 2002 \\
& 12.4 & 0.84 & 0.24 & 0.24 & Matsui et al., 1984 \\
& 16 & 0.86 & 0.23 & 0.26 & \\
\hline Pig & 33.5 & 1.1 & 0.198 & - & Cavalier et al., 1997 \\
\hline Goat & 27.5 & 1.44 & 0.24 & 0.37 & Ismail, 2005c \\
& 25.8 & 1.5 & 0.27 & 0.28 & Tiwari et al., 2009 \\
Mean & 26.7 & 1.5 & 0.15 & 0.32 & \\
\hline Cow & 550 & 1.02 & 0.30 & - & Kumar et al., 2010 \\
& 80 & 1.58 & 0.19 & 0.20 & Maradiya et al., 2010 \\
Mean & 315 & 1.3 & 0.25 & 0.2 & \\
\hline Sheep & 25.8 & 1.21 & 0.24 & 0.27 & Swati et al., 2010 \\
& 42.6 & 1.47 & 0.16 & 0.39 & Guerrini et al., 1985 \\
Mean & 34.2 & 1.34 & 0.2 & 0.33 & \\
\hline Buffalo & 85 & 1.27 & 0.26 & 0.36 & Gohil et al., 2009 \\
\hline Camel & 420 & 2.57 & 0.11 & 0.32 & Goudah A., 2008 \\
\hline Horse & 400 & 1.62 & 0.31 & 0.33 & Ringger et al., 1996 \\
\hline
\end{tabular}

$\mathrm{W}$ - body weight; $\mathrm{t}_{1 / 2}$ - elimination half life; $\mathrm{Cl}_{\mathrm{B}}$ - total body clearance; $\mathrm{V}_{\mathrm{ss}}-$ steady state volume of distribution.

\section{$\mathrm{Y}=\mathrm{a} \cdot \mathrm{W}^{\mathrm{b}}$ (Equation 1)}

where $Y$ is the value of the respective pharmacokinetic parameter $\left(\mathrm{t}_{1 / 2 \beta} ; \mathrm{V}_{\mathrm{ss}}\right.$ or $\left.\mathrm{Cl}_{\mathrm{B}}\right), a$ is the coefficient equal to antilog of $c$ from Equation 2, W is the body weight and $b$ - the exponent of the allometric equation. The logarithmic transformation of Equation 1 gives:

$\log \mathrm{Y}=\log \mathrm{c}+\mathrm{b} \cdot \log \mathrm{W}$ (Equation 2)

where $Y$ is $\mathrm{t}_{1 / 2 \beta}, \mathrm{V}_{\mathrm{ss}}$ or $\mathrm{Cl}_{\mathrm{B}}, \log c$ is the $\mathrm{y}$ intercept and $b$ : the slope.

The least squares linear regression method was used for estimation of correlation between pharmacokinetic parameters of interest and body weight. Statistical analysis was done by Statistica 6.1 software (Statistica for Windows, StatSoft. Inc., Tulsa, OK, USA).

\section{RESULTS}

The results from the regression analysis are listed in Table 5. The values of the exponent $b$ for $t_{1 / 2 \beta}$ were lower than the theoretical value of 0.25 for all four cephalosporins. The value for cephalexin was even negative. The correlation between $t_{1 / 2 \beta}$ values and body weight were statistically significant only for cefepime and ceftriaxone. The highest value of $y$ intercept $(a)$ for $t_{1 / 2 \beta}$ was calculated for cephalexin (1.45) and the lowest for cefquinome $(0.65)$. The values of $b$ for $\mathrm{V}_{\text {ss }}$ and $\mathrm{Cl}_{\mathrm{B}}$ ranged between 0.79 and 0.99 , respectively 0.68 and 1.05 for all studied drugs. Statistically significant relationship was found between body weight and $V_{s s}$ 
as well as between body weight and $\mathrm{Cl}_{\mathrm{B}}$ for all substances analysed (Table 5). The highest $\mathrm{y}$-intercept $(a)$ for $\mathrm{V}_{\mathrm{ss}}$ was found for ceftriaxone. The y-intercept values for cephalexin, cefepime and cefquinome were much lower. The lowest value of $\mathrm{Cl}_{\mathrm{B}}$ $y$-intercept was calculated for cefquinome and the highest: for ceftriaxone. The equations based on the calculations which could be used for estimation of the respective pharmacokinetic parameters are as follows:

Cephalexin: $\mathrm{Cl}_{\mathrm{B}}=0.20 \mathrm{~W}^{1.05} ; \mathrm{V}_{\mathrm{ss}}=0.32 \mathrm{~W}^{0.98}$; Cefepime: $\mathrm{t}_{1 / 2 \beta}=1.03 \mathrm{~W}^{0.16} ; \mathrm{Cl}_{\mathrm{B}}=0.35 \mathrm{~W}^{0.68}$; $\mathrm{V}_{\mathrm{ss}}=0.13 \mathrm{~W}^{0.99}$;

Ceftriaxone: $\mathrm{t}_{1 / 2 \beta}=0.83 \mathrm{~W}^{0.13}$;

$\mathrm{Cl}_{\mathrm{B}}=0.76 \mathrm{~W}^{0.73} ; \mathrm{V}_{\mathrm{ss}}=0.82 \mathrm{~W}^{0.79}$;
Cefquinome: $\mathrm{Cl}_{\mathrm{B}}=0.22 \mathrm{~W}^{0.875}$; $\mathrm{V}_{\mathrm{ss}}=0.298 \mathrm{~W}^{0.975}$.

\section{DISCUSSION}

Simple allometric scaling is an attractive alternative to provide reliable predictions of $t_{1 / 2 \beta}, V_{s s}$ and $\mathrm{Cl}_{B}$. Despite the risk of deviation of estimated values from the observed pharmacokinetic parameters in some cases, interspecies scaling could be used to analyse the pharmacokinetic behaviour of drugs in veterinary medicine, it provides good explanations for the observed differences between animal species (Mahmood, 2007). The experience with allometric scaling shows that after inclusion of large number of analysed data (from as many as possible animal species

Table 5. Allometric relationship between body clearance, volume of distribution and elimination half-life of cephalosporin antibiotics on the body mass in mammalian species

\begin{tabular}{llllll}
\hline Antibiotic & Parameters & $\mathrm{n}$ & $\mathrm{t}_{1 / 2 \beta}$ & \multicolumn{1}{c}{$\mathrm{Cl}_{\mathrm{B}}$} & \multicolumn{1}{c}{$\mathrm{V}_{\mathrm{ss}}$} \\
\hline \multirow{3}{*}{ Cefepime } & $a$ & 11 & 1.03 & 0.348 & 0.33 \\
& $b$ & 11 & 0.163 & 0.68 & 0.99 \\
& $r$ & 10 & 0.82 & 0.981 & 0.981 \\
& $\mathrm{P}$ & & $<0.01$ & $<0.001$ & $<0.001$ \\
\hline \multirow{3}{*}{ Cefquinome } & $a$ & 8 & 1.05 & 0.220 & 0.298 \\
& $b$ & 8 & 0.165 & 0.875 & 0.975 \\
& $r$ & 8 & 0.332 & 0.910 & 0.984 \\
Cephalexin & $\mathrm{P}$ & & $>0.05$ & $<0.001$ & $<0.001$ \\
& $a$ & 7 & 1.45 & 0.203 & 0.32 \\
& $b$ & 7 & -0.005 & 1.048 & 0.978 \\
Ceftriaxone & $r$ & 7 & -0.210 & 0.985 & 0.992 \\
& $\mathrm{P}$ & & $>0.05$ & $<0.001$ & $<0.001$ \\
\hline & $a$ & 11 & 0.83 & 0.757 & 0.819 \\
Ceftiofur* & $b$ & 11 & 0.13 & 0.727 & 0.790 \\
& $r$ & 11 & 0.823 & 0.946 & 0.959 \\
& $\mathrm{P}$ & & $<0.01$ & $<0.001$ & $<0.001$ \\
\hline
\end{tabular}

*Data are taken from Haritova $\&$ Lashev (2012). $a$ - allometric coefficient, $b$ - allometric exponent, $r$ - correlation coefficient, $\mathrm{P}-$ level of significance. 
Allometric analysis of the pharmacokinetics of four cephalosporin antibiotics in mammals

Table 6. Ratios of predicted vs. observed pharmacokinetic parameters (\%)e for cephalexin, cefepime, cefquinome and ceftriaxone in mammalian species.

\begin{tabular}{|c|c|c|c|c|c|c|c|c|}
\hline \multirow[b]{2}{*}{ Parameter } & \multicolumn{2}{|c|}{ Cephalexin } & \multicolumn{2}{|c|}{ Cefepime } & \multicolumn{2}{|c|}{ Cefquinome } & \multicolumn{2}{|c|}{ Ceftriaxone } \\
\hline & $\mathrm{Cl}_{\mathrm{B}}$ & $\mathrm{V}_{\mathrm{ss}}$ & $\mathrm{Cl}_{\mathrm{B}}$ & $\mathrm{V}_{\mathrm{ss}}$ & $\mathrm{Cl}_{\mathrm{B}}$ & $\mathrm{V}_{\mathrm{ss}}$ & $\mathrm{Cl}_{\mathrm{B}}$ & $\mathrm{V}_{\mathrm{ss}}$ \\
\hline Mouse & 95 & 79 & 76.6 & 97 & & & 22.8 & 26.26 \\
\hline Rat & 100 & 94 & 77 & 92 & & & & \\
\hline Rabbit & & & 119 & 45 & 116 & 138 & & \\
\hline Cat & & & & & & & 130 & 100 \\
\hline Dog & 63 & 125 & 131 & 320 & 75 & 125 & 156 & 177 \\
\hline Monkey & & & 181 & 128 & & & & \\
\hline Pig & & & & & 75 & 73 & & \\
\hline Sheep & & & 74.5 & 86.5 & 41 & 76 & 145 & 118 \\
\hline Goat & 66 & 187 & 110 & 91.4 & 250 & 75 & 206 & 128 \\
\hline Cow & 40 & 72 & 86 & 103 & 92 & 115 & 64 & 125 \\
\hline Buffalo & 171 & 71 & 95.3 & 76 & 200 & 100 & 85 & 89 \\
\hline Horse & 118 & 116 & 68 & & 85 & 117 & 45 & 70 \\
\hline Camel & & & 120 & 310 & & & 127 & 70 \\
\hline
\end{tabular}

as well as individual studies for each species) the method can provide precise values of estimated parameters (Mahmood \& Balian, 1999; Mahmood, 2007). Results of previous studies confirm this observation. Therefore, in the present study, as many as possible data reported in the literature were used. Dividing animal species in groups according to their physiological characteristics additionally improves the predictive power (Mahmood, 2007). For example, the excretion function of kidneys, which is important for the elimination rate of cephalosporins, is different in mammals than in birds. These differences lead to less correct estimations of pharmacokinetic parameters by allometric scaling analysis. That is why only data for mammalian species were included in the present calculations. The examined cephalosporin antibiotics have similar pharmacokinetic properties - low level of distributions and fast elimination. They are not metabolised in the organism and are eliminated mainly by renal excretion in the urine, which makes allometric scal- ing valuable (Mahmood, 2007; Hunter et $a l ., 2008)$. The allometric exponent $b$ for pharmacokinetic parameters, such as body clearance and volume of distribution, related to physiological processes ranges from 0.67 to 1 (Riviere et al., 1997). The theoretical value for the volume of distribution is 1 assuming that total body water directly correlates to body weight and the volume of distribution is a function of total body water. Our results for the analysed substances are close to the theoretical. Theoretical value of allometric exponent $b$ for volume of distribution $\left(\mathrm{V}_{\mathrm{ss}}\right)$ is equal to 1. Our results for cephalosporins in mammals are very close to 1 , with high correlation coefficient and low P-value, which allow us accepting that $\mathrm{V}_{\text {ss }}$ correlates with body weight. This pharmacokinetic parameter could be predicted successfully for investigated cefalosporins.

It is widely accepted that the metabolic rate is propotional to body mass raised to the three-quarter power $\left(\mathrm{W}^{0.75}\right)$. The overall renal and hepatic functions are related to blood flow, which is dependent on car- 
diac output, scaled to $b$ equal to 0.75 . This is true especially for drugs that did not undergo significant metabolic conversion (Mahmood \& Balian, 1999; Mahmood, 2007). Our values of $b$ for total body clearance vary between 0.68 and 1 . This could be explaned by the chemical properties of substances, number of species included, variations in experimental design, and inter-laboratory variability. In any case the values of $b$ do not differ statistically from the theoretical value of 0.75 . The presented data are close to the reported for ceftiofur (Haritova \& Lashev, 2012).

Grouping of animal species in clusters according to their affiliation to different orders improves allometric scaling as it has been demonstrated in previous investigations (Kirkwood \& Merriam, 1990; Mahmood, 2007; Haritova \& Lashev, 2009). The findings of Hunter et al. (2008) suggest that better prediction of the pharmacokinetic parameters and dosage regimen for birds are generated when using only avian data and that improvements in prediction are seen in drugs that are renally excreted. Ideally, one should scale values of $\mathrm{Cl}_{\mathrm{B}}$ for compounds that are excreted, without metabolism through kidneys. In the current study we dealt with drugs that are metabolised at a low extent. The exponent 0.75 was widely applied for $\mathrm{Cl}_{\mathrm{B}}$ but it is based on basal metabolic rate and usage of this fixed value can result in wrong predictions (Mahmood, 2007). According to Mahmood \& Balian (1999) $b$ values between 0.7 and 1 allow for a relatively proper prediction of $\mathrm{Cl}_{\mathrm{B}}$.

The most difficult for successful scaling are the values of $t_{1 / 2 \beta}$ (Mahmood, 2007; Hunter et al., 2008). As a secondary parameter it is derived from scaling to $\mathrm{V}_{\mathrm{ss}} / \mathrm{Cl}_{\mathrm{B}}$. In case of perfect correlation between body weight and last two parameters, value of $b$ for $\mathrm{t}_{1 / 2 \beta}$ would approxi- mate to 0.25 . Such case has been reported for quinolones in mammals and birds where $b$ was lower than 0.25 (Cox et al., 2004; Cox, 2007; Haritova \& Lashev, 2009). The same was registered for the investigated five cephalosporins (including ceftiofur). So our calculations showed lack (cephalexin and cefquinome) or presence of low association (cefepime and ceftriaxone) between $t_{1 / 2 \beta}$ values and body weight for all analysed substances.

The majority of calculated values are sufficiently close to the experimental. Exceptions are the values of cephalexin clearance in cows and buffaloes and the volume of distribution in goats. Different cefepime clearance is observed in monkeys and volume of distribution: in dogs, rabbits, goats and camels. For cefquinome the differences in clearance values are in sheep, goats and buffaloes, while for ceftriaxone - in mice, goats, horses. The volume of distribution of ceftriaxone was different in mice.

In conclusion, the values of $\mathrm{Cl}_{\mathrm{B}}$ and $\mathrm{V}_{\text {ss }}$ of cephalexin, cefepime, cefquinome, ceftriaxone show significant correlation with the body weight of mammals. The values of the respective coefficient $b$ are close to the theoretical ones. Such relationships for $t_{1 / 2 \beta}$ were detected only for cefepime and ceftriaxone, but not for cephalexin and cefquinome. The ratios between the calculated and experimental values for included cephalosporins varied at a different extent. For some species they are different from 1 (lower or higher). These variations are related also to the influence of various factors such as animal breed or methodological differences. They are not a reason to accept discussed relationships as invalid. These differences can be interpreted rather as criteria for the objectivity of the experimental data included in the calculations. The 
published findings could be used for prediction of pharmacokinetic parameters in rare wild and exotic species or for firstin-animal dose selection.

\section{REFERENCES}

Abd El Aty, A., A. Goudah, S. Mouneir, Y. Sunwoo, J. Jang, J. Shin, J. Shim \& M. Shimoda, 2007. Acute-phase response alters the disposition kinetics of cefepime following intravenous administration to rabbits. Veterinary Research Communications, 31, 67-75.

Albarelos, G. A., V. E. Kreil \& M. F. Landoni, 2007. Pharmacokinetics of ceftriaxone after intravenous, intramusculsr and subcutaneous administration to domestic cats. Journal of Veterinary Pharmacology and Therapeutics, 30, 345-352.

Albarelos, G. A., L. Montoya, P. C. Quaine \& M. F. Landoni, 2011. Pharmacokinetics and bioavailability of a long-acting formulation of cephalexin after intramuscular administration to cats. Research in Veterinary Science, 91, 129-131.

Ambros, L., V. Kreil, L. Tarragona, A. Monferinotti, R. Hallu \& M. Rebuelto, 2010. Comparative pharmacokinetics of intravenous cephalexin in pregnant, lactating, and nonpregnant, nonlactating goats. Journal of Veterinary Pharmacology and Therapeutics, 34, 397-402.

Bu, B., H. Sexton, X. Fan, P. Torres, P. Houston, I. Heiman \& L. Liu, 2010. The novel sensitive and high throughput determination of cefepime in mouse plasma by SCXLC/MS/MS method following off-line $\mu$ Elution 96-well solid-phase extraction to support systemic antibiotic programs. Journal of Chromatography B, 878, 1623 1628.

Carli, S., P. Anfossi, R. Villa, G. Castellani, G. Mengozzi \& C. Montesissa, 1999. Absorption kinetics and bioavailability of cephalexin in the dog after oral and intramuscular administration. Journal of Vete- rinary Pharmacology and Therapeutics, 22, 308-313.

Cavalier, A., D. Leveque, J. Peter, J. Salmon, H.E. Li, Y. Salmon, P. Nobelis, J. Geisert, H. Monteil \& F. Jehl, 1997. Pharmacokinetic Interaction between itraconazole and ceftriaxone in Yucatan miniature pigs. $A n$ timicrobial Agents and Chemotherapy, 41, 2029-2032.

Chicoine, A., W. Cox, L. Huang, G. Ang \& P. Dowling, 2009. Bioavailability and pharmacokinetics of a novel cephalexin oral paste formulation in fed and fasted dogs Journal of Veterinary Pharmacology and Therapeutics, 32, 400-402.

Cox, S. K., 2007. Allometric scaling of marbofloxacin, moxifloxacin, danofloxacin and difloxacin pharmacokinetics: A retrospectives analysis. Journal of Veterinary Pharmacology and Therapeutics, 30, 381-386.

Cox, S. K., M. B. Cottrell, L. Smith, M. Papich, D. L. Frasier \& J. Bartges, 2004. Allometric analysis of ciprofloxacin and enrofloxacin pharmacokinetics across species Journal of Veterinary Pharmacology and Therapeutics, 27, 139-146.

Davis, J., J. Salmon \& M. Papich, 2005. Pharmacokinetics and tissue fluid distribution of cephalexin in the horse after oral and i.v. administration. Journal of Veterinary Pharmacology and Therapeutics, 28, 425431.

Dinev, T. G., 2008. Comparison of the pharmacokinetics of five aminoglycoside and aminocyclitol antibiotics using allometric analysis in mammal and bird species. Research in Veterinary Science, 84, 107-118.

Dinakaran, V., V. K. Dumka, B. Ranjan, R. Balaje \& P. Sidhu, 2013. Pharmacokinetics following intravenous administration and pharmacodinamics of cefquinome in buffalo calves. Tropical Animal Health and Production, 45, 1509-1512.

Dumka, V. K., V. Dinakaran, B. Ranjan \& S. Rampal, 2013. Comparative pharmacokinetics of cefquinome following intravenous and intramuscular administration 
in goats. Small Ruminant Research, 113, 273-277.

Forgue, S., W. Shyu, C. Gleason, K. Pittman \& R. Barbhaiya, 1987. Pharmacokinetics of the novel cephalosporin cefepime (BMY-28142) in rats and monkeys. Antimicrobial Agents and Chemotherapy, 31, 799-804.

Gardner, S. Y. \& M. Papich, 2001. Comparison of cefepime pharmacokinetics in neonatal foals and adult dogs, Journal of Veterinary Pharmacology and Therapeutics, 24, 187-192.

Garg, S. K., R. K. Chaudhary, A. K. Srivastava \& B. D. Garg, 1990. Pharmacokinetics and dosage regimen of cephalexin in buffalo calves (Bubalus bubalis) following single intravenous and intramuscular administration. Veterinary Research Communication, 14, 59-62.

Garg, S. K., R. K. Chaudhary \& A. K. Srivastava, 1996. Pharmacokinetics of cephalexin in calves after intravenous and subcutaneous administration. Acta Veterinaria Hungarica, 44, 195-201.

Gohil, P. V., U. D. Patel, S. K. Bhavsar \& A. M. Thaker, 2009. Pharmacokinetics of ceftriaxone in buffalo calves (Bubalus bubalis) following intravenous and intramuscular administration. Iranian Journal of Veterinary Research, 10, 33-37.

Goudah, A., 2008. Pharmacokinetic parameters of ceftriaxone after single intravenous and intramuscular administration in camels (Camelus dromedarius). Research in Veterinary Science, 84, 483-489.

Goudah, A., H. Shin, I. Kim, B. Chang, J. Shim \& A. Abd El Aty, 2009. Evaluation of single dose pharmacokinetics of cefepime in healthy bull camels (Camelus dromedaries). Journal of Veterinary Pharmacology and Therapeutics, 32, 393-396.

Guerrini, V., L. Filippich, G. Cao, P. English \& D. Bourne, 1985. Pharmacokinetics of cefaronide, ceftriaxone and cefoperazone in sheep. Journal of Veterinary Pharmacology and Therapeutics, 8, 120-127.
Guglick, M., C. Macallister \& C. Clarke, 1998. Pharmacokinetics of cefepime and comparison with those of ceftiofur in horses. American Journal of Veterinary Research, 56, 458-463.

Haritova, A. \& L. Lashev, 2009. Comparison of the pharmacokinetics of seven fluoroquinolones in mammalian and bird species using allometric analysis. Bulgarian Journal of Veterinary Medicine, 12, 3-24.

Haritova, A. \& L. Lashev, 2012. Bridging pharmacokinetics between herbivorous mammal species by allometric analysis: A case study of ceftiofur. Acta Veterinaria (Beograd), 62, 207-211.

Hunter, R., 2010. Interspecies Allometric Scaling. Handbook of Experimental Pharmacology, 199, 139-157.

Hunter, R. P., I. Mahmood \& M. N. Martinez, 2008. Prediction of xenobiotic clearance in avian species using mammalian or avian data: How accurate is the prediction? Journal of Veterinary Pharmacology and Therapeutics, 31, 281-284.

Hwang, Y., I. Song, H. Lee, T. Kim, M. Kim, J. Lim, B. Park \& H. Yun, 2011. Pharmacokinetics and bioavailability of cefquinome in rabbits following intravenous and intramuscular administration. Journal of Veterinary Pharmacology and Therapeutics, 34, 618-620.

Ismail, M., 2005a. Disposition kinetics, bioavailability and renal clearance of cefepime in calves. Veterinary Research Communications, 29, 69-79.

Ismail, M., 2005b. Pharmacokinetics of cefepime administered by i.v. and i.m. routes to ewes. Journal of Veterinary Pharmacology and Therapeutics, 28, 499-503.

Ismail, M., 2005c. Pharmacokinetics, urinary and mammary excretion of ceftriaxone in lactating goats. Journal of Veterinary Medicine A, 52, 354-358.

Joshi, B. \& S. K. Sharma, 2007. Pharmacokinetic disposition and bioavailability of cefepime in buffalo calves. Journal of Veterinary Pharmacology and Therapeutics, 30, 500-502. 
Kirkwood, J. K. \& J. Merriam, 1990. Variation in plasma half-life of gentamicin between species in relation to body weight and taxonomy. Research in Veteriinary Science, 49, 160-165.

Kumar, S., A. K. Srivastava, V. K. Dumka \& N. Kumar, 2010. Plasma pharmacokinetics and milk levels of ceftriaxone following single intravenous administration in healthy and endometritic cows. Veterinary Research Communications, 34, 503-510.

Lashev, L. \& A. Haritova, 2007. Comparative allometric analysis of pharmacokinetics of florfenicol and thiamphenicol. Bulgarian Journal of Veterinary Medicine, 9, 115-122.

Lee, S., S. K. Kim, D. Y. Lee, S. Y. Chae \& Y. Byun, 2006. Pharmacokinetics of a new, orally available ceftriaxone formulation in physical complexation with a cationic analogue of bile acid in rats. Antimicrobial Agents and Chemotherapy, 50, 1869-1871.

Li, X., W. Wu, D. Su, Z. Wang, H. Jiang, \& J. Shen, 2008. Pharmacokinetics and bioavailability of cefquinome in healthy piglets. Journal of Veterinary Pharmacology and Therapeutics, 31, 523-527.

Limbert, M., D. Isert, N. Klesel, A. Markus, K. Seeger, G. Seibert \& E. Schrinner, 1991. Antibacterial activities in vitro and in vivo and pharmacokinetics of cefquinome (HR $111 \mathrm{~V})$, a new broad-spectrum cephalosporin. Antimicrobial Agents and Chemotherapy, 35, 14-19.

Liu, B., C. Zhang, X. Zhang, Y. Yang, J. Yu, J. Sun \& Y. Liu, 2012. Pharmacokinetics and bioavailability of cefquinome in crossbred wild boars. Journal of Veterinary Pharmacology and Therapeutics, 35, 611614.

Mahmood, I. \& J. D. Balian, 1999. The pharmacokinetic principles behind scaling from preclinical results to phase I protocols. Clinical Pharmacokinetics, 36, 1-11.

Mahmood, I., 2007. Application of allometric principles for the prediction of pharmacokinetics in human and veterinary drug development. Advanced Drug Delivery Reviews, 59, 1177-1192.

Maradiya, J., H. Goriya, S. Bhavsar, U. Patel \& A. Thaker, 2010. Pharmacokinetics of ceftriaxone in calves. Veterinarski Arhiv, 80, 1-9.

Mathe, A., K. Komka, M. Forczig, D. Szabo, P. Anderlik \& F. Rozgonyi, 2006. The effect of different doses of cisplatin on the pharmacokinetic parameters of cefepime in mice. Laboratory Animals, 40, 296-300.

Matsui, H., M. Komiya, C. Ikeda \& A. Tachibana, 1984. Comparative pharmacokinetics of YM-13115, ceftriaxone, and ceftazidime in rats, dogs and Rhesus monkeys. Antimicrobial Agents and Chemotherapy, 24, 204-207.

Mckechnie, A. E. \& B. O. Wolf, 2004. The allometry of avian basal metabolic rate: Good predictions need good data. Physiological and Biochemical Zoology, 77, 502-521.

Mordenti, J., 1985. Forecasting cephalosporin and monobactam antibiotic half-lives in humans form data collected in laboratory animals, Antimicrobial Agents and Chemotherapy, 27, 887-891.

Pashov, D., L. Lashev, I. Matev \& I. Kanelov, 1997. Interspecies comparisons of plasma half-life of trimethoprim in relation to body mass Journal of Veterinary Pharmacology and Therapeutics, 20, 48-53.

Patani, K., U. Patel, S. Bhavsar, A. Thaker \& J. Sarvaiya, 2008. Single dose pharmacokinetics of cefepime after intravenous and intramuscular administration in goats. Turkish Journal of Veterinary and Animal Science, 32, 159-162.

Patel, P., U. Patel, S. Bhavsar \& A. Thaker, 2009. Pharmacokinetics of cefepime following intravenous and intramuscular administration in sheep. Iranian Journal of Pharmacology and Therapeutics, 9, 7-10.

Patel, U., S. Bhavsar \& A. Thaker, 2006. Pharmacokinetics and dosage regimen of cefepime following single dose intravenous administration in calves. Journal of 
Pharmacology and Therapeutics, 5, 127 130.

Pawar, Y. \& S. Sharma, 2008. Influence of $E$. coli lipopolysaccharide induced fever on the plasma kinetics of cefepime in crossbred calves. Veterinary Research Coтmunications, 32, 123-130.

Prados, A., V. Kreil, L. Tarragona, P. Quaine, P. Monfrinotti \& M. Rebuelto, 2008. El meloxicam no modifica la disposicionde la cefalexina en caninos. InVet, 10, 21-36.

Prawez, S., R. Raina, D. Dimitrova, N. Pankaj, A. Ahmad \& P. Verma, 2010. The pharmacokinetics of cefepime in goats following single-dose i.v. and i.m. administration. Turkish Journal of Veterinary and Animal Science, 34, 427-431.

Rebuelto, M., G. Albarellos, L. Ambros, L. Montoya, R. Bonafine, P. Otero \& R. Hallu, 2002. Pharmacokinetics of ceftriaxone administered by intravenous, intramuscular of subcutaneous routs to dogs. Journal of Veterinary Pharmacology and Therapeutics, 25, 73-76.

Ringger, N., E. Pearson, R. Gronwall \& S. Kohlepp, 1996. Pharmacokinetics of ceftriaxone in healthy horses, Equine Veterinary Journal, 28, 476-479.

Riviere, J. E., T. Martin-Jimenez, S. Sundlof \& A. Craigmill, 1997. Interspecies allometric analysis of the comparative pharmacokinetics of 44 drugs across veterinary and laboratory animal species. Journal of Veterinary Pharmacology and Therapeutics, 20, 453-463.

Rule, R., M. Vita, H. Baschar \& O. Farina, 2008. Pharmacokinetics and penetration into tissue fluid of cefepime administered to hyperthermic rabbits. Acta Bioquimica Clinica Latinoamericana, 42, 221-225.

Smiet, E., A. Haritova, B. Heil, J. FinkGremels \& I. Wijnberg, 2012. Comparing the pharmacokinetics of a fourth generation cephalosporin in three different age groups of New Forest ponies. Equine Veteriary Journal, Suppl., 41, 52-56.

Soback, S., G. Ziv, A. Bor \& M. Shapira, 1988. Pharmacokinetics of cephalexin gly- cinate in lactating cows and ewes. Journal of Veterinary Medicine A, 35, 755-760.

Swati, S., S. Tiwari, U. Patel, S. Bhavsar \& A. Thaker, 2010. Pharmacokinetics and bioavailability of ceftriaxone in Patanwadi sheep. VetScan, 5, 45-50.

Tiwari, S., S. Swati, S. Bhavsar, U. Patel \& A. Thaker, 2009. Disposition of ceftriaxone in goats (Capra hircus). VetScan, 4, 21-26.

Uney, K., F. Altan \& M. Elmas, 2011. Development and validation of a high-performance liquid chromatography method for determination of cefquinome concentrations in sheep plasma and its application to pharmacokinetic studies. Antimicrobial Agents and Chemotherapy, 55, 854-859.

Villa, R., C. Belloli, P. Cangardi, O. Sonzogni, S. Bacchetta \& S. Carli, 2002. Pharmacokinetics of cephalexin in the horse after intravenous and intramuscular administration of two formulations. The Veterinary Journal, 164, 74-76.

Wang, E., Y. Bergeron \& M. Bergeron, 2005. Ceftriaxone pharmacokinetics in interleukin-10-treated murine pneumococcal pneumonia. Journal of Antimicrobials and Chemotherapy, 55, 721-726.

Zhang, J., C. Wang, Q. Liu, Q. Meng, J. Cang, H. Sun, Y. Gao, T. Kaku \& K. Liu, 2010. Pharmacokinetic interaction between JBP485 and cephalexin in rats. Drug $\mathrm{Me}$ tabolism and Disposition, 38, 930-938.

Paper received 24.08.2015; accepted for publication 22.01.2016

\section{Correspondence:}

Prof. Lubomir D. Lashev

Department of Pharmacology, Physiology and Physiological Chemistry, Faculty of Veterinary Medicine, Trakia University, 6000 Stara Zagora, Bulgaria e-mail: lashev@uni-sz.bg 